\section{Leadership, culture, intellectual capital and knowledge processes for organizational innovativeness across industries: the case of Poland}

Leadership, culture, intellectual capital

\author{
Wioleta Kucharska
}

Management, Faculty of Management and Economics, Gdansk University of Technology, Gdansk, Poland
Received 5 February 2021 Revised 22 April 2021 1 July 2021

27 September 2021 Accepted 1 October 2021

\begin{abstract}
Purpose - This study aims to present the overview of intellectual capital creation micro-mechanisms concerning formal and informal knowledge processes. The organizational culture, transformational leadership and innovativeness are also included in the investigation as ascendants and consequences of the focal relation of intellectual capital and knowledge processes.

Design/methodology/approach - Based on a sample of 1,418 Polish knowledge workers from the construction, healthcare, higher education and information technology (IT) industries, the empirical model was developed using the structural equation modeling (SEM) method.

Findings - The study exposes that the essence of transformational leadership innovativeness oriented is developing all intellectual capital components. To do so, leaders must support both formal and informal knowledge processes through the organizational culture of knowledge and learning. Furthermore, for best results of the knowledge transformation into intellectual capital, the learning culture must be shaped by both components: learning climate and acceptance of mistakes.

Practical implications - Presented findings can be directly applied to organizations to enhance innovativeness. Namely, leaders who observe that the more knowledge is formally managed in their organizations, the less effective the knowledge exchange is-should put more effort into supporting informal knowledge processes to smoothly develop human and relational intellectual capital components. Shortly, leaders must implement an authentic learning culture, including the mistakes acceptance component, to use the full organizational potential to achieve intellectual capital growth. Intellectual capital growth is essential for innovativeness.

Originality/value - This study presents the "big picture" of all intellectual capital creation micromechanisms linking transformational leadership with organizational innovativeness and explains the "knowledge paradox" identified by Mabey and Zhao (2017). This explanation assumes that intellectual capital components are created informally (i.e. human and relational ones) and formally (i.e. structural ones). Therefore, for best effects, both formal and informal knowledge processes, must be supported. Furthermore, this study exposes that the intensity of all explored micro-mechanisms is industry-specific.
\end{abstract}

Keywords Learning culture, Knowledge culture, Transformational leadership, Innovations, Intellectual capital, Tacit knowledge, Knowledge processes, Healthcare industry, Higher education, IT industry,

Construction industry, Gender studies

Paper type Research paper

(C) Wioleta Kucharska. Published by Emerald Publishing Limited. This article is published under the Creative Commons Attribution (CC BY 4.0) licence. Anyone may reproduce, distribute, translate and create derivative works of this article (for both commercial and non-commercial purposes), subject to full attribution to the original publication and authors. The full terms of this licence may be seen at http:// creativecommons.org/licences/by/4.0/legalcode

The presented research is a result of the project Tacit Knowledge Sharing Influence on Innovativeness. The Sector Analysis No. UMO-2018/31/D/HS4/02623 is financed by the funds of the National Science Center of Poland (Narodowe Centrum Nauki-NCN).

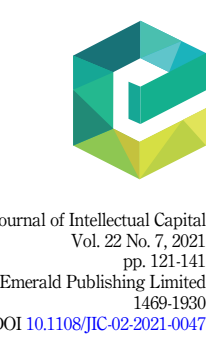




\section{Introduction}

Intellectual capital (IC) is a central focus of knowledge-driven companies today. It is believed there is no knowledge without IC and vice versa (Rastogi, 2000). Therefore, studies exploring this bidirectional relationship (Garcia-Perez et al., 2020) are vital for organizational development because they strive to understand this relationship and they help organizations shape their policies in favor of creating both knowledge and IC.

This study focuses on IC creation arising from knowledge processes and contributes to the literature by demonstrating how tacit and explicit knowledge affect IC. This exploration is needed to understand the contradiction identified by Mabey and Zhao (2017), who revealed that "the more knowledge is formally managed, the less likely effective knowledge exchange will occur" (p. 43); they named this phenomenon the "knowledge paradox." Solving the mechanism of this paradox is vital for knowledge management theory and practice; however, following Rastogi (2000) and Garcia-Perez et al. (2020), this only seems possible through a more in-depth investigation of ICrelated and knowledge management-related organizational processes. This exploration is needed because tacit and explicit knowledge forms are created differently across the organization, which might affect IC. Specifically, this study aims to expose how informal processes of tacit knowledge and formal processes of explicit knowledge influence each component of IC.

Both tacit and explicit knowledge are important in IC development. Moreover, while each IC component (i.e. human, relational, structural and renewal) is vital for organizational performance and development (Ahmed et al., 2019), they require different types of organizational support (Matricano et al., 2020). This study provides an in-depth exploration of how these four IC components contribute to organizational innovativeness performance. Specifically, it shows how the components are created through formal and informal knowledge processes when shaped by organizational culture and driven by transformational leadership, resulting in IC followed by innovativeness. Moreover, Watkins and Kim (2018) stated that if the assumption that organizational learning culture enhances knowledge creation and innovation is empirically confirmed, it is a highly significant discovery. Thus, the ambition to deliver this proof justifies this study's profound complexity.

Further, in a comprehensive literature review, Bellucci et al. (2021) noted the urgent need for studies conducting in-depth explorations of the interconnections between knowledge management, IC, and market performance with innovation. This study, strongly inspired by the literature presented above, directly responds to this call.

Moreover, it is argued that transformational leadership is a key factor in enhancing learning, knowledge, and innovation relations (Klaic et al., 2020). Alrowwad et al. (2020) demonstrated that transformational leadership affects innovation through IC and presented the general mechanisms of this effect. This study aims to delve deeper to reveal the micromechanisms.

\section{Theoretical framework}

All of the factors mentioned so far are related. However, the "big picture" of all IC creation micromechanisms linking transformational leadership with organizational innovativeness is still missing. Moreover, the issue of how formal and informal knowledge processes shape IC and the overall relationship between leadership and innovativeness remains unexplored. While some extant studies demonstrate a link between leadership, organizational innovativeness, and the factors of culture, IC and knowledge processes (e.g. Pellegrini et al, 2020), they explain focal parts of the relationship rather than its entire structure. This study aims to fill this gap. A deeper understanding of the essence of the aforementioned relations is important for transformational leadership and innovativeness relation exploration, which is vital for learning organizations' growth. Moreover, revealing these micromechanisms is critical for:

(1) understanding how particular IC components in organizations are developed as a result of knowledge processes (Garcia-Perez et al., 2020; Matricano et al., 2020). 
(2) explaining the "knowledge paradox" (Mabey and Zhao, 2017).

(3) providing empirical proof supporting the theoretical thesis that learning culture influences organizational innovativeness (Watkins and Kim, 2018).

This knowledge is desired by theory and practice to improve organizational innovativeness.

Leadership, culture, intellectual capital

\subsection{Research question}

This study aims to answer the following research question: How do formal and informal knowledge processes shape IC and link the overall relationship between transformational leadership and innovativeness due to company culture?

\subsection{Research problem}

The research problem addressed in this study concerns transformational leadership and the innovativeness of learning organizations. All factors mentioned in the Introduction section are related, but the details are not known. This lack of knowledge makes it impossible to understand the micromechanisms linking transformational leadership with organizational innovativeness; this understanding is desired by theory and practice to improve organizational innovativeness.

\section{$2.3 \mathrm{Aim}$}

This study aims to present an overview of IC creation micromechanisms of formal and informal knowledge processes driven by organizational culture and transformational leadership to achieve innovativeness. Specific objectives that support the general aim will:

(1) clarify how the IC components are created in the organization in the relation to knowledge processes.

(2) explain the "knowledge paradox."

(3) deliver empirical proof verifying whether learning culture influences organizational innovativeness.

\section{Hypotheses}

\subsection{Transformational leadership shapes organizational culture}

Transformational leaders are a prominent group because they establish organizational ideas and visions, create strong bonds with employees, motivate employees, and are supportive and inspirational (Busari et al., 2019). Such leaders are able to effect change through the development of organizational culture (Brandt et al., 2019). However, leaders sometimes focus too much on changing organizational policies rather than changing the organizational mindset, often failing to improve performance as a result (Schwartz, 2018). Thus, this study focuses on transformational leadership that actively shapes organizational culture to ensure good innovation performance of learning organizations. Learning organizations facilitate the learning process of all employees, continuously transforming themselves (Peler et al., 1989). Therefore, a desire to possess knowledge is a motivation for learning. Given that learning always changes the perception of things, leaders should support an organizational culture focused on knowledge, learning, and innovativeness at the individual and organizational levels (Watkins and Marsick, 1996), and facilitating the flow of constant transformation of tacit knowledge into explicit knowledge (Nonaka et al., 2000). Further, learning organizations are a formal management system, whereas organizational learning is an activity that occurs as a result of formal systemic enhancements and even without them (Werner, 2017). 
$\mathrm{JIC}$ 22,7

Therefore, a learning culture that is understood as employees' positive attitudes and behaviors toward learning processes is vital for formal and informal organizational learning processes.

Naqshbandi and Jasimuddin (2018) demonstrated that knowledge-oriented leadership affects knowledge management capability, which is broadly defined as creating infrastructure and processes to increase innovativeness. These researchers followed Donate and de Pablo (2015), who found that a knowledge-oriented company culture influences knowledge management practices, and that knowledge processes are supported by leadership. Transformational leadership supports knowledge sharing (Coun et al., 2019) and creates an organizational culture that promotes knowledge, learning, and innovativeness (Anselmann and Mulder, 2020). Therefore, the following hypotheses are proposed:

H1. Transformational leadership has a positive effect on the culture of learning.

H2. Transformational leadership has a positive effect on the organizational culture of knowledge.

The spontaneous flow and exchange of tacit knowledge require strong leadership to create favorable conditions for doing so (Mabey and Nicholds, 2015). According to Mabey and Zhao (2017, p. 48), intentional leadership "based on a collaborative ethic is necessary for the creation of a 'shared' space to promote informal knowledge exchange". Leaders must facilitate such learning interactions to transform tacit knowledge into explicit knowledge. To support knowledge sharing, organizations also need to develop a culture in which employees can learn, unlearn, and relearn in a safe climate (Nold, 2012). Farnese et al. (2019) also demonstrated the importance of culture for overall organizational learning. Boh and Wong (2013) noted that organizational climate is vital for learning. Moreover, leadership positively affects the psychological safety climate of organizations, with this climate mediating the relationship between leadership and tacit knowledge sharing (Shao et al., 2017). Given that the climate component promotes learning and the mistake acceptance component forms learning culture (Kucharska and Bedford, 2020), the following hypotheses are proposed:

H1a. Transformational leadership has a positive effect on the climate component of learning culture.

H1b. Transformational leadership has a positive effect on the mistake acceptance component of learning culture.

Employees with learning mindsets are open to changes and "are ready to be wrong" (Senge, 2006), meaning they accept the occurrence of mistakes and learn from them. Zappa and Robins (2016) stressed that the essence of organizational learning is to identify and modify mistakes. Thus, as demonstrated by Kucharska and Bedford (2020) and Kucharska (2021), the climate component of learning culture supports the acceptance of mistakes in the learning process. Therefore, the following hypothesis is formulated:

H1c. The climate component of learning culture supports the mistake acceptance component.

\subsection{Knowledge culture affects learning culture}

Organizational culture facilitates the creation and distribution of knowledge (Aramburu et al., 2015). Islam et al. (2015) defined knowledge culture as one that has the conditions to support the flow of knowledge across the organization. Watkins and Marsick (1996, p. 4) noted that "a learning organization must capture, share, and use knowledge so its members can work together to change the way the organization responds to challenges. People must question the old, socially constructed, and maintained ways of thinking. Learning must take place and be 
supported in teams and larger groups, where individuals can mutually create new knowledge. And the process must be continuous because becoming a learning organization is a never-ending journey." In light of this, learning culture is crucial for organizations but is ineffective without the implemented culture of knowledge. Pérez López et al. (2004) and Kucharska and Bedford (2020) argued that there is no learning culture without knowledge culture. Eid and Nuhu (2011) also noted the significant effect of knowledge culture on learning. Therefore, the following hypotheses are proposed:

$H 3 a$. Knowledge culture has a positive effect on the climate component of learning culture.

$H 3 b$. Knowledge culture has a positive effect on the mistake acceptance component of learning culture.

\subsection{Organizational culture shapes knowledge processes}

Knowledge is the "life blood of most organizations today" (Mabey and Zhao, 2017, p. 39). Thus, the principal focus of organizations is to create and maintain conditions and processes for using knowledge and creating a competitive advantage (Leone and Schiavone, 2019). Inkpen and Tsang (2005) emphasized that access to knowledge is important but not sufficient for effective knowledge capturing and sharing. Moreover, Heisig (2009) noted that, apart from knowledge processes, technology, and entire organization design, human-oriented factors such as culture and leadership are critical to ensure the successful implementation of knowledge management that effects are visible in performance. Furthermore, an organization's knowledge culture can shape employees' positive attitudes toward (tacit and explicit) knowledge that supports the smooth flow of all knowledge processes. This assumption is justified by the fact that formal acts are caused by formal rules and policies, while informal acts are shaped by informal rules (North, 1990). Company culture accommodates both formal and informal rules. Knowledge (tacit and explicit), according to culture, is shared formally and informally.

The tacit component of knowledge reflects novelty. The distinction between the explicit and tacit components of knowledge is perfectly explained by Nonaka's et al. (2000) "ba" concept, which determines the moment of transforming the uncodified, often unconscious tacit knowledge into the conscious and easily codified explicit form. The sharing of both explicit and tacit knowledge is important and expected. It can also depend on the promise of perks and other motivational benefits (Shao et al., 2017) or the overall company culture focused on a positive attitude toward knowledge and learning. The understanding and appreciation of knowledge as a resource that is visible in knowledge culture lead to knowledge management and the development of formal knowledge processes. As a result, knowledge culture supports these processes (Intezari et al., 2017). Thus, the following hypothesis is proposed:

H4a. Knowledge culture has a positive effect on formal explicit knowledge processes.

In contrast to the explicit form of knowledge, which is expressed in words and data and codified into many easy-to-share forms (e.g. books, reports, documents, databases), tacit knowledge is personal, context-specific, stored in the human mind, and, undoubtedly, impossible to be formalized (Olaisen and Revang, 2018). Crane and Bontis (2014, p. 1136) defined tacit knowledge as "acquired unconsciously and automatically, but capable of influencing action". Most tacit knowledge processes occur inside the human mind. Most of them are unconscious, except when they are revealed and shared e.g. when knowledge workers actively collaborate (Asher and Popper, 2019). Therefore, tacit knowledge generation and sharing are not formalized or structured but depend on the knowledge owner's free will, while the factor supporting such sharing includes personal motives (e.g. altruistic motives or
Leadership, culture, intellectual capital 
JIC

22,7

126

desire for self-presentation associated with creating an impression of being an expert). Therefore, following Islam et al.'s (2015) statement that knowledge culture supports the flow of knowledge throughout the organization, it is assumed that knowledge culture might motivate knowledge workers to share their newly discovered thoughts and ideas. Thus, the following hypothesis is formulated:

$H 4 b$. Knowledge culture has a positive effect on tacit knowledge sharing.

Informal sharing is greatly dependent on social skills, cohesion, and the willingness to commit time and effort to share knowledge with others (Reagans and McEvily, 2003). Shao et al. (2012) revealed that tacit knowledge-sharing behaviors are motivated by psychological reasons and facilitated by contextual factors such as organizational climate. Garvin (1993, p. 80) defined an organization with a learning culture as an "organization skilled at creating, acquiring, and transferring knowledge, and at modifying its behavior to reflect new knowledge and insights". A culture that enables a channel of knowledge flow to be created greatly supports tacit knowledge sharing (Mabey and Zhao, 2017). Therefore, the following hypotheses are proposed:

H4c. The climate component of learning culture has a positive effect on tacit knowledge sharing (informal).

H4d. The mistake acceptance component of constant learning culture has a positive effect on tacit knowledge sharing (informal).

Following the distinction noted by Polanyi (1966) between tacit and explicit knowledge, Nonaka et al. (2000) transferred this understanding of knowledge to the business context introducing SECI model. Next, Nonaka and Takeuchi (2019) developed socialization, externalization, combination and internalization model, which emphasizes that organizational continuous innovation is achievable through constantly and repeatedly creating new knowledge (tacit), disseminating this knowledge, and converting it into an explicit form. Thus, the following hypothesis is proposed:

H5. Tacit knowledge sharing has a positive effect on formal explicit knowledge processes.

\subsection{Knowledge processes support intellectual capital creation}

IC is conceptualized as knowledge-based assets that organizations use to achieve and maintain a competitive advantage (Yang et al., 2015). Knowledge management processes and IC affect one another (Seleim and Khalil, 2011). IC results from the intangible assets of knowledge and social relationships (Jardon, 2015). The intangible assets of today are vital sources of innovativeness, which is the key driver to ensure long-term organizational competitiveness (Tsui et al., 2014). Moreover, intellectual assets are defined as the "stock of knowledge" possessed by an organization and comprises human, structural, and relational capital (Bontis, 1998). Human capital is related to employees' knowledge, capabilities, education level, soft and professional skills, and other personal characteristics. Structural capital reflects the entire knowledge infrastructure of an organization (Hussinki et al., 2017). The explicit knowledge acquisition and management of an organization are fundamental parts of structural capital (Abualoush et al., 2018). Structural capital is perceived as an effect of explicit knowledge integrated into information systems and as the result of knowledge conversion (Asiaei et al., 2018). Relational capital accumulates internal and external relationships as a source of potential value (Kianto and Waajakoski, 2010). Additionally, the renewal capital component of IC, introduced by Kianto (2008), reflects the general organizational ability to learn and acquire new skills and capabilities. 
Furthermore, Saint-Onge (1996) noted that tacit knowledge has different forms for each organizational IC component: for human capital, tacit knowledge is reflected in mindsets, assumptions, beliefs, and biases; for relational capital, tacit knowledge is reflected in the collective mindsets of meaning perception; and for structural capital, tacit knowledge is reflected in the collective culture, norms, and patterns of behavior (p. 12). Vagnoni and Oppi (2015) argued that newly created knowledge strongly supports structural capital. At the same time, formal knowledge management processes support structural capital creation (Abualoush et al., 2018). Thus, IC is a result of formal and informal knowledge processes and is the focal point of organizational performance. As a result, hypotheses that both formal (related to explicit knowledge) and informal (related to tacit knowledge) knowledge processes support IC are proposed. Further, Wang et al. (2014) demonstrated that the effects of tacit and explicit knowledge on specific IC components differ. Thus, the hypotheses are divided into tacit and explicit knowledge as follows:

H6a. Tacit knowledge sharing has a positive effect on human capital.

H6b. Tacit knowledge sharing has a positive effect on relational capital.

H6c. Tacit knowledge sharing has a positive effect on structural capital.

$H 7 a$. Explicit knowledge processes have a positive effect on human capital.

H7b. Explicit knowledge processes have a positive effect on relational capital.

$H 7 c$. Explicit knowledge processes have a positive effect on structural capital.

Agostini and Nosella (2017), Buenechea-Elberdin et al. (2018), and Oliveira et al. (2020) considered human capital an antecedent of relational capital. In addition, Kianto (2008) and Kianto et al. (2010) argued that renewal capital (reflecting the general organizational ability to learn and acquire new skills and capabilities) is supported by human capital. Thus, the following hypotheses are put forward:

H8a. Human capital has a positive effect on relational capital.

$H 8 b$. Human capital has a positive effect on renewal capital.

Santos-Rodrigues et al. (2013) noted that the human and relational components of IC are important for innovation development, and the relational and structural components of IC are vital for innovation adoption, demonstrating that relational capital is critical. Moreover, Buenechea-Elberdin et al. (2018) revealed that relational capital positively affects renewal capital. Therefore, the following hypothesis is formulated:

H9a. Relational capital has a positive effect on renewal capital.

The relational capital component of IC includes all company relationships (Meles et al., 2016). It can be perceived as a mandatory source of structural capital understood as infrastructure for value creation by sharing, using and transferring existing knowledge (Sullivan, 2000). Moreover, Lervik (2006) argued that structural and relational capital are interrelated. Thus, the following hypothesis is developed:

H9b. Relational capital has a positive effect on structural capital.

\subsection{Intellectual capital fosters organizational innovativeness}

Innovative ideas are at the center of organizational efforts aimed at delivering superior market performance and securing sustainable competitive advantages (Cillo et al., 2019). IC is a source of innovation (Campanella et al., 2014). Renewal capital (Kianto, 2008) is in line with Senge's (2006) idea that learning organizations have a shared vision of organizational aims,
Leadership, culture, intellectual capital 
JIC

22,7

128

and that open-mindedness accommodates diverse viewpoints, experimenting, questioning existing assumptions, and shared beliefs to promote continuous innovation. The direct and positive effect of IC on organizational innovativeness was demonstrated (Cabrilo et al., 2018). Buenechea-Elberdin et al. (2018) showed that structural capital has a positive effect on renewal capital and that renewal capital supports organizational innovation performance. Therefore, the following hypotheses are formulated:

H1O. Structural capital has a positive effect on renewal capital.

H11. Renewal capital has a positive effect on organizational innovativeness.

\subsection{Control variables}

A control variable is an additional factor possibly affecting the relationship between an independent and a dependent variable. As a result, a control variable may act as a confounder, moderator or suppressor (Spector and Brannick, 2011). Such an important variable for this study is tacit knowledge awareness. According to El-Den and Sriratanaviriyakul (2019), tacit knowledge awareness is simply the stage at which an individual realizes something new (e.g. opinion/idea). Social interactions foster awareness and the development of new concepts (Nonaka et al., 2000). Therefore, the tacit knowledge awareness moment is promoted by general socialization i.e. task-related interactions and overall formal, informal and unformal organizational social interactions (Insch et al., 2008). Moreover, Kremer et al. (2019, p. 67) highlighted that "if new ideas are not articulated, they can hardly be implemented." So, the lack of tacit knowledge awareness may disrupt its sharing. Therefore, it is considered a moderator in this study (Hayes, 2018). Thus, the following hypothesis is proposed:

Hcv1. Tacit knowledge awareness moderates the effect of learning culture on tacit knowledge sharing.

This study also aims to control the industry factor. Kucharska and Erickson (2020) empirically demonstrated that the industry factor is important for knowledge-sharing studies. Therefore, the comparison between involved in the study sectors seems to be fascinating. Specifically, all sectors included in this study (information technology [IT], healthcare, higher education [HE], construction) are defined as knowledge-based industries, but IT, healthcare, and HE are defined as knowledge-intensive industries (Lee and Jung, 2020). The above industries are driven by knowledge but in a different (industrial) context. Therefore, the following hypotheses are proposed concerning the potential effect of industry factors on informal tacit knowledge sharing and formal knowledge processes:

Hcv2a. Industry factor determines informal tacit knowledge sharing.

$H c v 2 b$. Industry factor determines formal knowledge processes.

Figure 1 visualizes theoretical model.

\section{Methodology}

\subsection{Sample}

The sampling process focused on recruiting knowledge worker staff from the IT, construction, $\mathrm{HE}$ and healthcare industries in Poland. The sampling plan included independent samples composed of $\mathrm{HE}(n=368)$ and construction, healthcare, and IT ( $n=350$ each) professionals. It was designed according to the statistics concerning the labor market (Statistics Poland, 2017). All samples were characterized by gender and position balance. The data were collected in January and February 2020. 


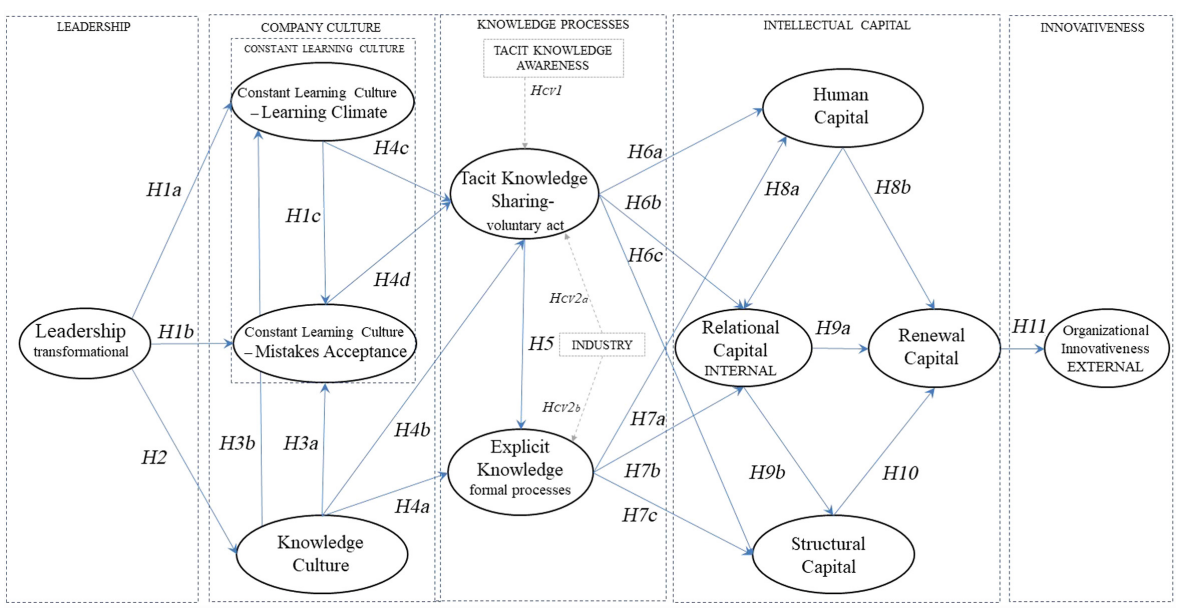

Leadership, culture, intellectual capital

129

The total variance of the samples was extracted at $73 \%$ (total Poland), $76 \%$ (construction), $74 \%$ (healthcare), $80 \%$ (IT), and 77\% (HE), while the Kaiser-Meyer-Olkin test of the samples' adequacy was obtained at levels 0.929 (total Poland), 0.885 (construction), 0.922 (healthcare), 0.896 (IT), and 0.936 (HE). All samples exceeded 0.6, which confirmed their good quality (Hair et al., 2010). Further, the Harman single-factor test (Fuller et al., 2016) was applied, and none of the results $-30 \%$ (total Poland), 29\% (construction), 34\% (healthcare), 29\% (IT), and 38\% (HE) - exceeded $50 \%$, confirming the quality of the datasets. Common method variance was detected at levels of $21 \%$ (total Poland), $27 \%$ (construction), $17 \%$ (healthcare), $36 \%$ (IT), and $19 \%$ (HE), confirming the accepted level of bias and justifying further analysis and presentation of the measures (Podsakoff and Organ, 1986). Appendix A presents sample details.

\subsection{Measures}

All included constructs represented by latent variables were measured using existing attitude scales (Appendix B). The new scale for knowledge processes measurement was introduced in this study and validated according to deVellis's (2017) procedure. The survey began with questions about the workers' qualifications to ensure the selection of respondents who: first, had been employed for a minimum of one year by the same company perceived by them as a "learning organization"; and second, had a "knowledge worker" status, which concerns positions where knowledge is a tool and the result of their work (input and output of their working processes). Respondents were given a brief explanation of the purpose of the study, and definitions of a learning organization, knowledge worker, and tacit knowledge. They were then asked to react to focal statements measuring all involved constructs using a seven-point Likert scale to assess respondents' attitudes to these statements. Further analysis only included fully completed questionnaires with $\mathrm{SD}>0.4$. Appendix $\mathrm{C}$ includes descriptive statistics.

The measured constructs reached (standardized) indicator loadings above the reference level of $>0.6$ (Hair et al., 2010). Internal consistency of the constructs was assessed using Cronbach's alpha and a critical level of $>0.7$ (Francis, 2001). Average variance extracted (AVE) was assessed with a test statistic of $>0.5$ and composite reliability of $>0.7$ (Byrne, 2016), with all establishing scale validity. Discriminant validity was assessed by comparing the AVE square root against correlations with other constructs (Fornell and Larcker, 1981). 
JIC

22,7

All AVE coefficients were appropriately larger than the reference value. Appendix D presents details.

\subsection{Procedure}

The analysis procedure began with an assessment of the structural model quality for total Poland. The control variable "industry" (nominal) was input to the total Poland model, and after the positive result achievement $\left(\beta=-0.10^{* * *}\right)$, separate models were created to identify differences between industries. Given that tacit knowledge awareness was included as a control variable and was also significant for the total Poland sample $\left(\beta=0.17^{* * * *}\right)$, it was also imputed for industry models. Next, all obtained results were analyzed and discussed.

\section{Results}

The most interesting findings concern the effect of knowledge processes on IC. Formal and informal knowledge processes were found to affect different IC components. Specifically, formal knowledge processes are not significant for relational capital, which is observed for all four industries under analysis (H7b). Similarly, formal knowledge processes are not significant for human capital (H7a), except in the HE and IT industries, but this support is not very strong $\left(\beta=0.11 * / 0.13^{*}\right)$. This implies that formal knowledge processes do not support human-related components of IC. In contrast, informal tacit knowledge sharing has a positive effect on all IC components (H6a), with the most potent effect observed for $\mathrm{HE}$ and healthcare $\left(\beta=0.61^{* * *} / 0.65^{* * *}\right)$. However, its influence on the structural component $(\mathrm{H} 6 \mathrm{c})$ is comparably weaker and not significant in the construction and HE industries. This implies that informal knowledge sharing supports human-related components of IC. Further, formal knowledge processes support the structural component, which is observed for all four industries under analysis (H7c). This implies that formal knowledge processes, in contrast to informal, strongly support the structural capital component. Renewal capital is strongly supported by human and structural capital (H8b and H10), whereas the positive effect of the relational component on renewal capital is noted only in the healthcare industry (H9a). This study reveals a strong effect of renewal capital on innovativeness for all four industries under consideration (H11). This highlights the importance of renewal capital for innovativeness.

Another important finding was the influence of knowledge culture and learning culture on formal and informal knowledge processes. The study finds that knowledge culture strongly influences the climate component of learning culture (H3b), and this relationship applies to all four industries. In contrast, the mistakes acceptance component of learning culture is strongly supported by knowledge culture in the construction and $\mathrm{HE}$ industries (H3a). For the healthcare industry, this relationship is weaker but still significant, and it is insignificant for the IT industry. Thus, the mistakes acceptance component of learning culture is not equally observed in all four industries, meaning that the potential of mistakes as a source of learning is not likely to be equally used in industries as a potential source of tacit knowledge awareness.

Moreover, the results demonstrate that knowledge culture strongly supports formal knowledge processes (H4a) and significantly and strongly supports informal tacit knowledge processes for the healthcare industry (H4b). For the IT industry, this relationship is weaker, and it is not significant for the construction and $\mathrm{HE}$ industries. In addition, it was discovered that learning culture is more important than knowledge culture for informal tacit knowledge sharing (H4c-d). The climate component of learning culture is found to have a significant and direct effect on tacit knowledge sharing in the construction, HE and IT industries (H4c). This effect is not significant in the healthcare industry. In contrast, the climate component of learning culture supports the mistakes acceptance component of learning culture in the 
healthcare and IT industries, but not in the HE and construction industries (H1c). This means that in the $\mathrm{HE}$ and construction industries, the acceptance of mistakes does not result from the learning climate component. In contrast to the construction and HE industries, learning climate significantly supports mistakes acceptance in the healthcare industry, and the relationship between learning climate and tacit knowledge sharing is fully mediated by mistakes acceptance (indirect effect $=0.20(* * *)$-two-tailed $\mathrm{BC}$ significance). Further, the acceptance of mistakes directly supports tacit knowledge sharing in the HE, healthcare, and construction industries, but not in the IT industry (H4d); however, learning climate supports mistakes acceptance in the IT industry (H4c). Thus, this issue is interesting and requires a more in-depth investigation. Moreover, in regard to the effect of knowledge culture on knowledge processes, the effect of tacit knowledge awareness on tacit knowledge sharing is the strongest in the healthcare industry (Hcv1), where the learning culture is the strongest and fully supported by the mistakes acceptance component.

Regarding leadership issues, it was found that transformational leadership significantly affects knowledge and learning cultures in all four analyzed industries (H1a-b, H2). However, while knowledge culture and learning climate are supported equally strongly by transformational leadership (H1b, H2), the mistakes acceptance component is supported by transformational leadership to a lesser extent. This suggests that the mistakes acceptance component of learning culture may be controversial for companies with strong knowledge culture. Specifically, companies where knowledge is highly valued may find it difficult to accept the fact that mistakes occur. This is in line with the learning paradox described by Kucharska and Bedford (2020). Figure 2 presents all the obtained results. All details of verifying the hypotheses are presented in Table 1.

\section{Discussion}

The results illustrate the "big picture" of all of the identified micromechanisms linking transformational leadership with organizational innovativeness. These micromechanisms

(1) clarified how the IC components are created in the relation to knowledge processes;

(2) explained the "knowledge paradox";

(3) exposed that IC development is industry-specific;

(4) delivered empirical proof that learning culture influences organizational innovativeness.

This contribution allows theory and practice to be expanded regarding organizational innovativeness. These findings are elaborated on below.

\subsection{Knowledge paradox is explained by the difference in intellectual capital components creation}

The most interesting finding of the study is that formal knowledge processes affect structural capital but are not significant in the development of human and relational capital. In contrast, the informal processes of tacit knowledge sharing have a far greater effect on human and relational capital than on structural capital. This finding is in line with Mabey and Zhao (2017), who found that more formal knowledge processes lead to less effective knowledge exchange. Mabey and Zhao (2017, p. 43) revealed that "the more knowledge is formally managed, the less likely effective knowledge exchange will occur" (i.e. "knowledge paradox"). They noted that for organizations of all types (i.e. business and science-oriented), benefits from explicit knowledge management are supported by an appropriate set of processes. However, such processes are not effective for tacit knowledge utilization. The present study 
$\mathrm{JIC}$
22,7

132

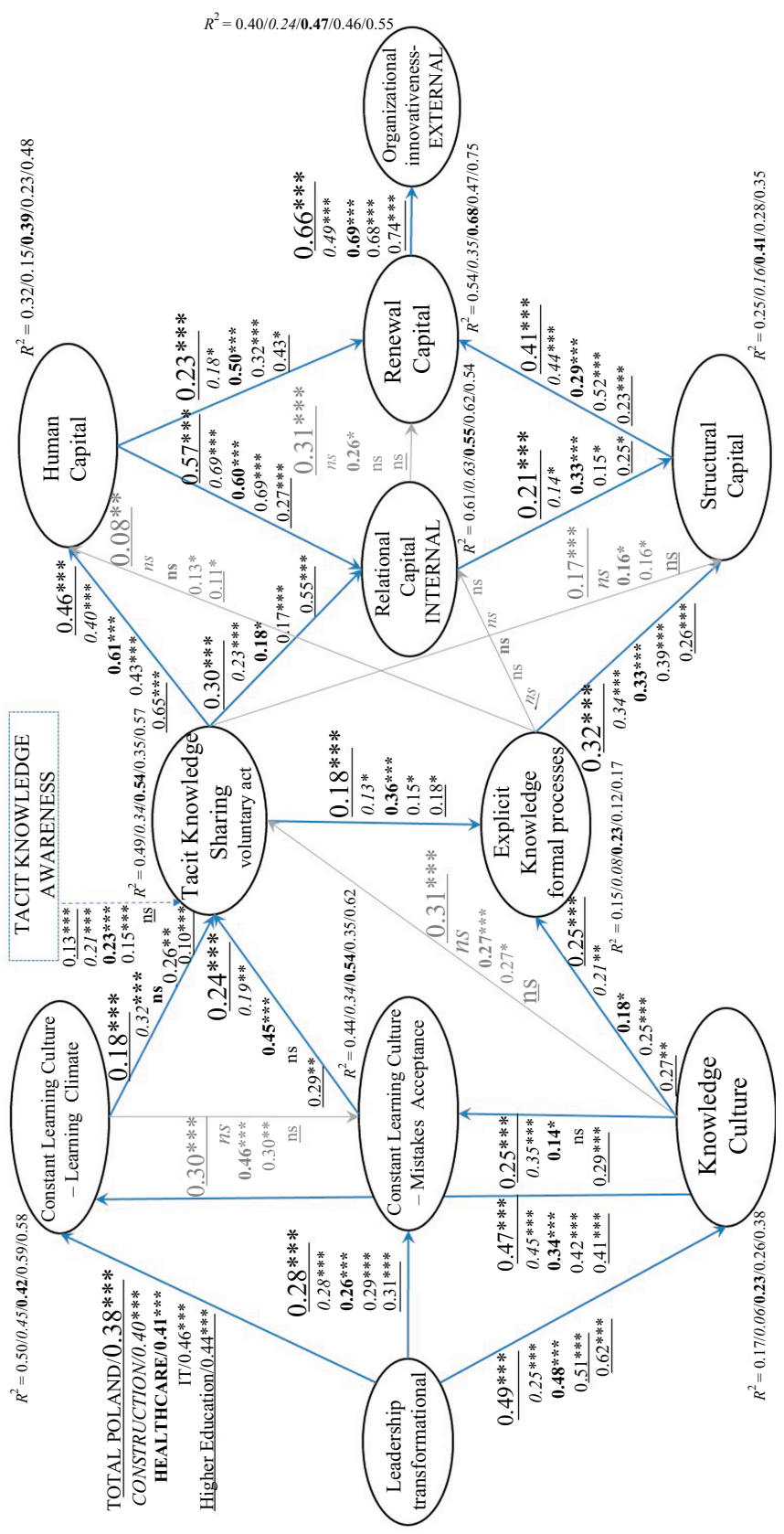

ฉㅇำ

$\begin{array}{lll}0 & 0 & \overline{0} \\ \text { II } & \text { II } & \circ\end{array}$

当当少

$\ddot{0} \ddot{\infty} \exists$

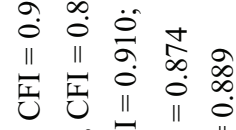

ஸ்

仓ั0

॥ $\|$

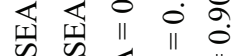

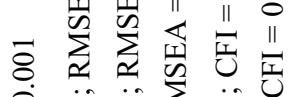

$\dot{0} \ddot{\dot{H}} \ddot{\nabla} \sum \ddot{\theta} \dot{0}$

* +

*

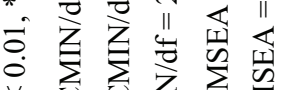

V $\sum_{i} \sum \sum_{\Omega}^{n}$

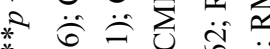

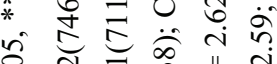

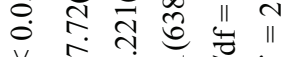

*

*

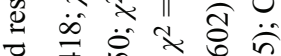

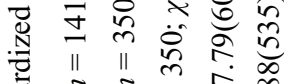

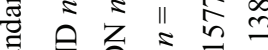

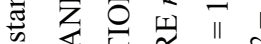

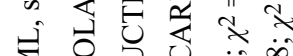

$\sum 0$

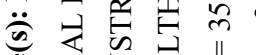

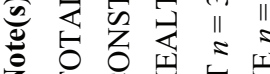

Figure 2.

Structural model 


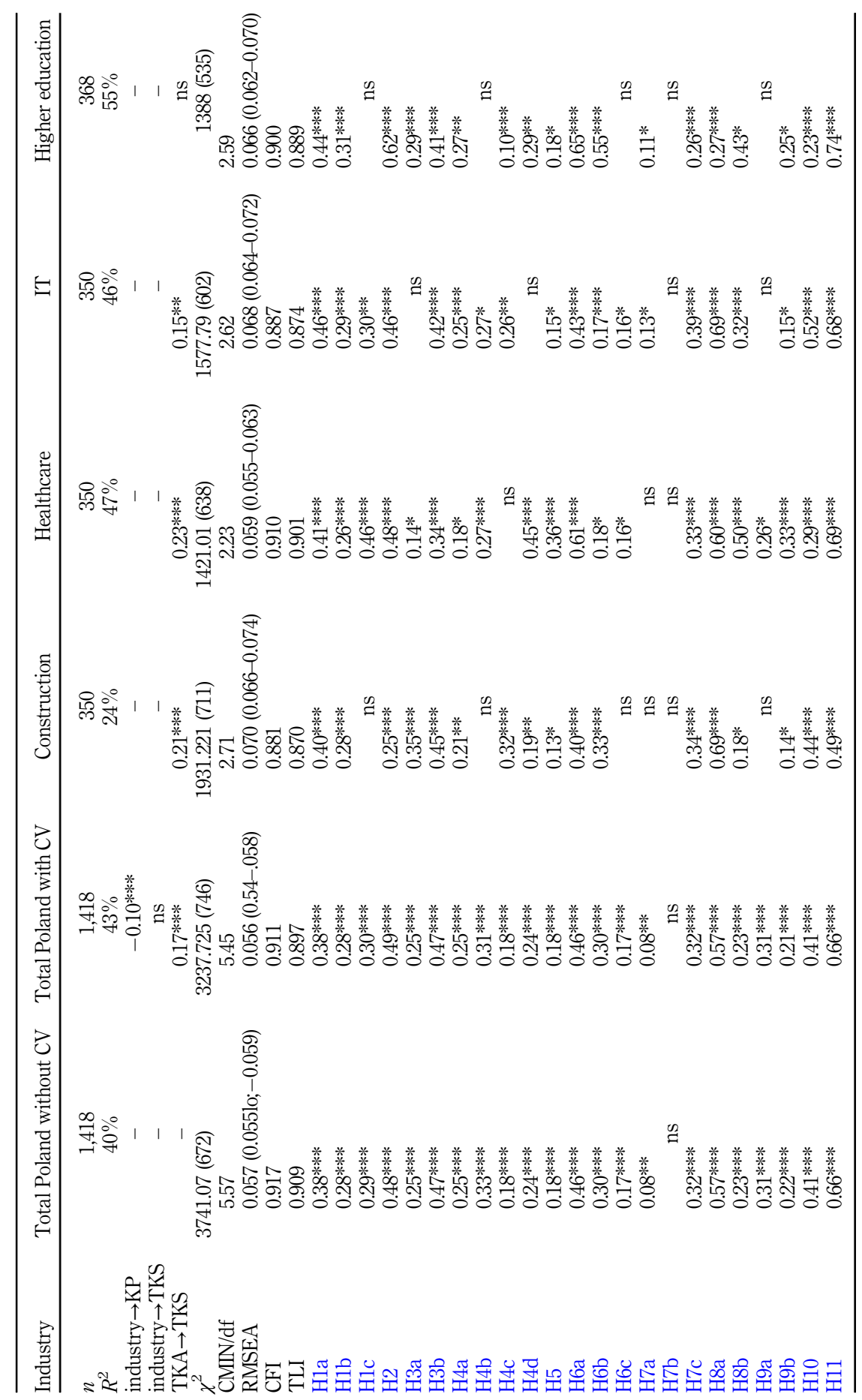

Leadership, culture, intellectual capital

133

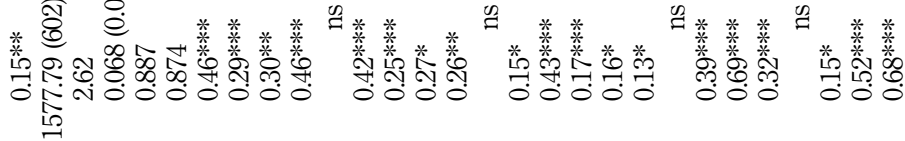

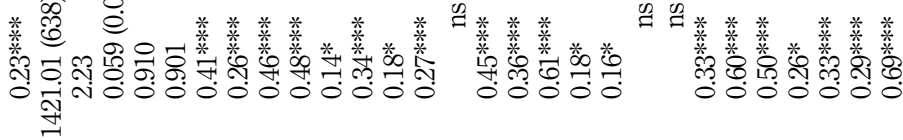

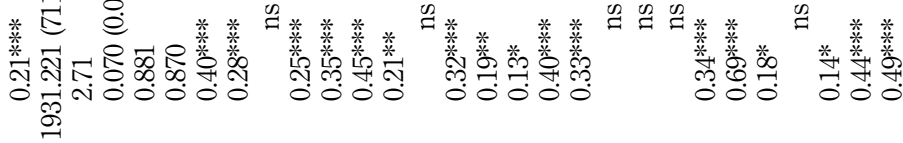


JIC

22,7

134

sheds light on this by explaining why this paradox occurs. Based on the results, formal knowledge processes support human capital development only in the IT industry $\left(\beta=0.13^{*}\right)$, and these processes are ineffective for relational capital creation, even in the IT industry. However, voluntary tacit knowledge sharing significantly supports human and relational capital in all industries. Still, the influence of tacit knowledge sharing on structural capital is weak for healthcare and IT ( $\left.\beta=0.16^{*} / \mathrm{both}\right)$, and it is not significant in the HE and construction industries. In contrast, formal processes are not effective for the human and relational components of IC. Wang et al.'s (2014) quantitative study in the context of technology companies in China also identified the lack of a significant effect of explicit knowledge sharing on relational capital, but noted its significant effect on human capital.

\subsection{Intellectual capital creation is industry-specific}

Presented results exposed that IC development is industry specific. The IT industry is exceptionally peculiar about IC creation through formal and informal knowledge processes. This specificity is also clear when the mistakes acceptance component of learning culture is considered. This component is not supported by knowledge culture in the IT industry and does not support informal tacit knowledge sharing, whereas the learning climate component supports informal tacit knowledge sharing in IT. Thus, the unique results of the present study and of Mabey and Zhao (2017) show that the IT industry should be studied in greater depth.

There are also interesting conclusions that apply to the construction industry, particularly given that the $R^{2}$ level obtained for this industry was half $\left(R^{2}=24 \%\right)$ of that obtained for the healthcare, IT and HE industries ( $47 \%, 46 \%$ and $55 \%$, respectively). In the construction industry, transformational leadership supports learning culture more than it supports knowledge culture. Further, learning climate significantly affects tacit knowledge sharing, which influences human and relational capital and does not influence structural capital, whereas it does in IT and healthcare. The other difference between the construction industry and other industries is that although human capital is strongly created by tacit knowledge sharing and strongly influences relational capital, its effect on structural capital is only significant to a lesser extent, and it does not support renewal capital. In the construction industry, structural capital is supported by formal knowledge processes and is the main source of renewal capital. Thus, external innovativeness in the construction industry is created by a source similar to that in the IT industry (i.e. mainly from new technologies created outside the company). While innovativeness is supported from the outside in the healthcare industry, it is principally fostered by human and relational capital from inside the organization (i.e. from dynamic intelligence and cooperation). This might be the result of the working environment. The IT and construction industries are more static and predictable than the healthcare industry, which requires knowledge to be in use on a continuous basis.

Striking findings are observed for the HE industry. Formal and informal knowledge processes support human capital. Still, their effect on renewal capital is much lower than that observed for healthcare and IT. Further, the observed influence of the human component on $\mathrm{HE}$ is the weakest among all of the analyzed industries. Relational capital in HE barely supports structural capital and, ultimately, does not support the renewal component. This means that even though human capital in the HE industry is more efficiently created and prominently supported by leadership, company culture, and knowledge processes than in other industries, it is not exploited effectively. The highest obtained innovativeness for HE could be even higher if the human capital component supported relational capital to a greater extent. Thus, the weakest part of IC creation in HE is internal relational capital. Still, it is generally a grave problem that is observed for all industries involved in this study, except for healthcare. 
In summary, the presented $R^{2}$ for the models of involved industries (Table 1) shows that the examined relations structure explains the explored phenomenon significantly differently for all included industries. Namely, the whole model explains external innovativeness in $55 \%$ for $\mathrm{HE}$; for healthcare and IT, it is $47 \%$ and $46 \%$, respectively, and only $24 \%$ for the construction industry. So, it exposes that IC development leading to innovativeness thanks to formal and informal knowledge processes is industry-specific.
Leadership, culture, intellectual capital

\subsection{Learning culture meaning for innovativeness is empirically proved}

Following Watkins and Kim (2018), the Introduction section noted that if the assumption that organizational learning culture enhances knowledge creation and innovation is empirically confirmed, it is a highly significant discovery. The theoretical consequences of the findings concerning the "knowledge paradox" identified by Mabey and Zhao (2017) deliver this evidence. Namely, this paradox is explained due to the identified structure of micromechanisms linking transformational leadership with organizational innovativeness. The essence of the presented explanation is an important element of delivering empirical evidence for learning culture's influence on innovativeness. That is, the presented knowledge paradox's essence is that the particular components of IC are created due to different knowledge processes; specifically, human and relational capital are created mostly informally, whereas structural capital is created mostly formally. Therefore, organizations focusing on formal knowledge processes may lose the tacit knowledge created by informal processes that are strongly supported by learning culture. This study revealed that learning culture and tacit knowledge sharing are vital for IC's human and relational components. It showed that the renewal component supported by other components is vital for innovativeness. Hence, this study demonstrates the importance of learning culture for all IC components and shows how these components are connected and how vital they are in terms of organizational innovativeness. Thus, the expected empirical proof of learning culture's influence on innovativeness has been delivered.

\section{Implications, future research and limitations}

The general practical context of the study findings suggests that for the effective development of all IC components, organizations must think and act more holistically and support the formal and informal flow of knowledge equally. Therefore, organizations must create formal solutions supporting a company culture that is focused not only on the management of knowledge assets (knowledge culture), but also on knowledge creation (i.e. on learning culture that fosters an appropriate climate and includes a mistake acceptance component).

In summary, the existing differences between different industries leave significant room for further studies in gender or national contexts and their interpretation. The issue of why tacit knowledge sharing in the IT industry is apparently weaker than in the healthcare and $\mathrm{HE}$ industries, but the IT industry is still one of the most innovative industries, remains unexplored. Is leadership the essence of IT success? Strong leaders established giants such as Apple, Microsoft, Facebook, and Amazon. The main reason might be the one mentioned above - the nature of work (clear rules, mathematical algorithms, logic) - in which case the "industry" control variable becomes the primary determinant for the type of knowledge sharing (explicit vs tacit, formal vs informal) and could imply different patterns of IC creation and its relation to the innovativeness of the company - depending on the industry sector. It might also be that the national context, including national culture and the maturity level of a particular industry, is important in terms of further findings. This issue is undoubtedly fascinating and deserves further investigation. 
$\mathrm{JIC}$

22,7

The principal limitation of the study - apart from the omission of external relational capital and the potential effect of the existing domination of men in the IT and construction sectors - is that this study was conducted in the context of only one country. Thus, the results may not be generalizable to other countries. Future research could include a cross-country study to shed light on the explored mechanisms of the effect of transformational leadership on company culture, knowledge processes, IC and innovativeness in knowledge-intensive organizations.

\section{Conclusions}

The essence of this study was the exposition of the overall relationship between leadership and innovativeness. Therefore, the current study presented the "big picture" of all IC creation micromechanisms linking transformational leadership with organizational innovativeness. As a result, it explained empirically the "knowledge paradox" identified by Mabey and Zhao (2017, p. 43), according to which "the more knowledge is formally managed, the less likely effective knowledge exchange will occur." The idea behind this paradox is that IC components are created informally (i.e. human and relational) and formally (i.e. structural). Therefore, organizations that focus too much on formal knowledge processes might lose the tacit knowledge created by informal processes. To avoid this, leaders must support both knowledge culture and learning culture. Learning culture encourages tacit knowledge sharing, which is vital for the growth of IC's human and relational components. At the same time, knowledge culture fosters formal knowledge processes for structural component development. Therefore, transformational leaders should equally support learning culture and knowledge culture - and, thanks to this effort-formal and informal knowledge processes to develop intellectual capital. This is vital for innovativeness and organizational development as a whole.

\section{References}

Abualoush, S., Masa'deh, R., Bataineh, K. and Alrowwad, A. (2018), "The role of knowledge management process and intellectual capital as intermediary variables between knowledge management infrastructure and organization performance", Interdisciplinary Journal of Information, Knowledge, and Management, Vol. 13, pp. 279-309, doi: 10.28945/4088.

Agostini, L. and Nosella, A. (2017), "Enhancing radical innovation performance through intellectual capital components", Journal of Intellectual Capital, Vol. 18 No. 4, pp. 789-806.

Ahmed, S.S., Guozhu, J., Mubarik, S., Khan, M. and Khan, E. (2019), "Intellectual capital and business performance: the role of dimensions of absorptive capacity", Journal of Intellectual Capital, Vol. 21 No. 1, pp. 23-39, doi: 10.1108/JIC-11-2018-0199.

Alrowwad, A., Abualoush, S.H. and Masa'deh, R. (2020), "Innovation and intellectual capital as intermediary variables among transformational leadership, transactional leadership, and organizational performance", Journal of Management Development, Vol. 39 No. 2, pp. 196-222, doi: 10.1108/jmd-02-2019-0062.

Anselmann, V. and Mulder, R.H. (2020), "Transformational leadership, knowledge sharing and reflection, and work teams' performance: a structural equation modelling analysis", Journal of Nursing Management, Vol. 28 No. 7, pp. 1627-1634, doi: 10.1111/jonm.13118.

Aramburu, N., Sáenz, J. and Blanco, C. (2015), "Structural capital, innovation capability, and company performance in technology-based Colombian firms", Cuadernos de Gestión, Vol. 15 No. 1, pp. 39-60, doi: 10.5295/cdg.130427na.

Asher, D. and Popper, M. (2019), "Tacit knowledge as a multilayer phenomenon: the 'onion' model”, The Learning Organization, Vol. 26 No. 3, pp. 264-275, doi: 10.1108/TLO-06-2018-0105.

Asiaei, K., Jusoh, R. and Bontis, N. (2018), "Intellectual capital and performance measurement systems in Iran”, Journal of Intellectual Capital, Vol. 19 No. 2, pp. 294-320, doi: 10.1108/JC-11-2016-0125. 
Bellucci, M., Marzi, G., Orlando, B. and Ciampi, F. (2021), "Journal of intellectual capital: a review of emerging themes and future trends", Journal of Intellectual Capital, Vol. 22 No. 4, pp. 744-767, doi: 10.1108/JIC-10-2019-0239.

Boh, W.F. and Wong, S.S. (2013), "Organizational climate and perceived manager effectiveness: influencing perceived usefulness of knowledge sharing mechanisms", Journal of the Association for Information Systems, Vol. 14 No. 3, pp. 122-152.

Bontis, N. (1998), "Intellectual capital: an exploratory study that develops measures and models", Management Decision, Vol. 36 No. 2, pp. 63-76, doi: 10.1108/00251749810204142.

Brandt, E., Andersson, A. and Kjellstrom, S. (2019), "The future trip: a story of transformational change”, Journal of Organizational Change Management, Vol. 32 No. 7, pp. 669-686, doi: 10.1108/ JOCM-09-2017-0358.

Buenechea-Elberdin, M., Sáenz, J. and Kianto, A. (2018), "Knowledge management strategies, intellectual capital, and innovation performance: a comparison between high- and low-tech firms", Journal of Knowledge Management, Vol. 22 No. 8, pp. 1757-1781, doi: 10.1108/jkm-042017-0150.

Busari, A.H., Khan, S.N., Abdullah, S.M. and Mughal, Y.H. (2019), "Transformational leadership style, followership, and factors of employees' reactions towards organizational change", Journal of Asia Business Studies, Vol. 14 No. 2, pp. 181-209, doi: 10.1108/jabs-03-2018-0083.

Byrne, B.M. (2016), Structural Equation Modeling with AMOS, Routledge, Abingdon.

Cabrilo, S., Kianto, A. and Milic, B. (2018), "The effect of IC components on innovation performance in Serbian companies", VINE Journal of Information and Knowledge Management Systems, Vol. 48 No. 3, pp. 448-466, doi: 10.1108/VJIKMS-06-2016-0033.

Campanella, F., Peruta, M.R.D. and Del Giudice, M. (2014), "Creating conditions for innovative performance of science parks in Europe. How manage the intellectual capital for converting knowledge into organizational action", Journal of Intellectual Capital, Vol. 15 No. 4, pp. 576-596, doi: 10.1108/JIC-07-2014-0085.

Cillo, V., Petruzzelli, A.M., Ardito, L. and Del Giudice, M. (2019), "Understanding sustainable innovation: a systematic literature review", Corporate Social Responsibility and Environmental Management, Vol. 26 No. 5, pp. 1012-1025, doi: 10.1002/csr.1783.

Coun, M.J.H., Peters, C.P. and Blomme, R.J. (2019), “Let's share!' the mediating role of employees' selfdetermination in the relationship between transformational and shared leadership and perceived knowledge sharing among peers", European Management Journal, Vol. 37 No. 4, pp. 481-491, doi: 10.1016/j.emj.2018.12.001.

Crane, L. and Bontis, N. (2014), "Trouble with tacit: developing a new perspective and approach", Journal of Knowledge Management, Vol. 18 No. 6, pp. 1127-1140, doi: 10.1108/JKM-02-2014-0061.

deVellis, R.F. (2017), Scale Development: Theory and Applications, Sage, Thousand Oaks, CA.

Donate, M.J. and de Pablo, J.D.S. (2015), "The role of knowledge-oriented leadership in knowledge management practices and innovation", Journal of Business Research, Vol. 68 No. 2, pp. 360-370, doi: 10.1016/j.jbusres.2014.06.022.

Eid, M. and Nuhu, N. (2011), "Impact of learning culture and information technology use on knowledge sharing of Saudi students", Knowledge Management Research and Practice, Vol. 9 No. 1, pp. 48-57, doi: 10.1057/kmrp.2010.25.

El-Den, J. and Sriratanaviriyakul, N. (2019), "The role of opinions and ideas as types of tacit knowledge”, Procedia Computer Science, Vol. 161, pp. 23-31, doi: 10.1016/j.procs.2019.11.095.

Farnese, M., Zaghini, F., Caruso, R., Fida, R., Romagnoli, M. and Sili, A. (2019), "Managing care errors in the wards: the contribution of authentic leadership and error management culture", Leadership and Organization Development Journal, Vol. 40 No. 1, pp. 17-30.

Fornell, C. and Larcker, D.F. (1981), "Evaluating structural equation models with unobservable variables and measurement error", Journal of Marketing Research, Vol. 18 No. 1, pp. 39-50, doi: $10.1177 / 002224378101800104$.
Leadership, culture, intellectual capital 
JIC 22,7

Francis, G. (2001), Introduction to SPSS for Windows, 3rd ed., Pearson Education, Sydney.

Fuller, C.M., Simmering, M.J., Atinc, G., Atinc, Y. and Babin, B.J. (2016), "Common methods variance detection in business research", Journal of Business Research, Vol. 69 No. 8, pp. 3192-3198, doi: 10.1016/j.jbusres.2015.12.008.

Garcia-Perez, A., Ghio, A., Occhipinti, Z. and Verona, R. (2020), "Knowledge management and intellectual capital in knowledge-based organizations: a review and theoretical perspectives", Journal of Knowledge Management, Vol. 24 No. 7, pp. 1719-1754, doi: 10.1108/JKM-12-2019-0703.

Garvin, D.A. (1993), "Building a learning organization", Harvard Business Review, Vol. 71 No. 4, pp. $78-91$.

Hair, J.F., Anderson, R.E., Babin, B.J. and Black, W.C. (2010), Multivariate Data Analysis: A Global Perspective, Pearson Education, Upper Saddle River, NJ.

Hayes, A. (2018), Introduction to Mediation, Moderation and Conditional Process Analysis: A Regression-Based Approach, Guilford Press, New York, NY.

Heisig, P. (2009), "Harmonisation of knowledge management - comparing $160 \mathrm{KM}$ frameworks around the globe", Journal of Knowledge Management, Vol. 13 No. 4, pp. 4-31.

Hussinki, H., Ritala, P., Vanhala, M. and Kianto, A. (2017), "Intellectual capital, knowledge management practices and firm performance", Journal of Intellectual Capital, Vol. 18 No. 4, pp. 904-922, doi: 10.1108/JIC-11-2016-0116.

Inkpen, A. and Tsang, E. (2005), "Social capital, networks and knowledge transfer", Academy of Management Review, Vol. 30 No. 1, pp. 146-165, doi: 10.5465/amr.2005.15281445.

Insch, G.S., McIntyre, N. and Dawley, D. (2008), "Tacit knowledge: a refinement and empirical test of the academic tacit knowledge scale", The Journal of Psychology, Vol. 142 No. 6, pp. 561-580, doi: 10.3200/JRLP.142.6.561-580.

Intezari, A., Taskin, N. and Pauleen, D.J. (2017), "Looking beyond knowledge sharing: an integrative approach to knowledge management culture", Journal of Knowledge Management, Vol. 21 No. 2 , pp. 492-515.

Islam, M.Z., Jasimuddin, S.M. and Hasan, I. (2015), "Organizational culture, structure, technology infrastructure and knowledge sharing", VINE Journal of Information and Knowledge Management Systems, Vol. 45 No. 1, pp. 67-88, doi: 10.1108/VINE-05-2014-0037.

Jardon, M.C. (2015), "The use of intellectual capital to obtain competitive advantages in regional small and medium enterprises: empirical evidence from MNCs based in Malaysia", Knowledge Management Research and Practice, Vol. 13 No. 4, pp. 486-496, doi: 10.1057/kmrp.2014.4.

Kianto, A. and Waajakoski, J. (2010), "Linking social capital to organizational growth", Knowledge Management Research and Practice, Vol. 8 No. 1, pp. 4-14, doi: 10.1057/kmrp.2009.29.

Kianto, A., Hurmelinna-Laukkanen, P. and Ritala, P. (2010), "Intellectual capital in service- and product-oriented companies”, Journal of Intellectual Capital, Vol. 11 No. 3, pp. 305-325, doi: 10. 1108/14691931011064563.

Kianto, A. (2008), "Development and validation of a survey instrument for measuring organisational renewal capability", International Journal of Technology Management, Vol. 42 Nos 1-2, pp. 69-88, doi: 10.1504/IJTM.2008.018061.

Klaic, A., Burtscher, M.J. and Joans, K. (2020), "Fostering team innovation and learning by means of team-centric transformational leadership: the role of teamwork quality", Journal of Occupational and Organizational Psychology, Vol. 93 No. 4, pp. 942-966, doi: 10.1111/joop.12316.

Kremer, H., Villamor, I. and Aguinis, H. (2019), "Innovation leadership: best-practice recommendations for promoting employee creativity, voice, and knowledge sharing”, Business Horizons, Vol. 62 No. 1, pp. 65-74, doi: 10.1016/j.bushor.2018.08.010.

Kucharska, W. (2021), "Do mistakes acceptance foster innovation? Polish and US cross-country study of tacit knowledge sharing in IT", Journal of Knowledge Management, Vol. 25 No. 11, pp. 105-128, doi: 10.1108/JKM-12-2020-0922. 
Kucharska, W. and Bedford, D.A.D. (2020), "Love your mistakes! - they help you adapt to change. How do knowledge, collaboration and learning cultures foster organizational intelligence?", Journal of Organizational Change Management, Vol. 33 No. 7, pp. 1329-1354, doi: 10.1108/jocm02-2020-0052.

Kucharska, W. and Erickson, G.S. (2020), "The influence of IT-competency dimensions on job satisfaction, knowledge sharing and performance across industries", VINE Journal of Information and Knowledge Management Systems, Vol. 50 No. 3, pp. 387-407, doi: 10.1108/ VJIKMS-06-2019-0098.

Lee, J. and Jung, S. (2020), "Industrial land use planning and the growth of knowledge industry: location pattern of knowledge-intensive services and their determinants in the Seoul metropolitan area", Land Use Policy, Vol. 95, p. 104632, doi: 10.1016/j.landusepol.2020.104632.

Leone, D. and Schiavone, F. (2019), "Innovation and knowledge sharing in crowdfunding: how social dynamics affect project success", Technology Analysis and Strategic Management, Vol. 31 No. 7, pp. 803-816, doi: 10.1080/09537325.2018.1554858.

Lervik, E. (2006), Relational Capital: A Study on its Importance, Quantification and its Impact on Business Sectors and Markets, University of Oslo/Autonomous University of Madrid Economics and Management of Innovation and Technology Policy, Madrid.

Mabey, C. and Nicholds, A. (2015), "Discourses of knowledge across global networks: what can be learnt about knowledge leadership from the ATLAS collaboration?", International Business Review, Vol. 24 No. 1, pp. 43-54, doi: 10.1016/j.ibusrev.2014.05.007.

Mabey, C. and Zhao, S. (2017), "Managing five paradoxes of knowledge exchange in networked organizations: new priorities for HRM?", Human Resource Management Journal, Vol. 27 No. 1, pp. 39-57, doi: 10.1111/1748-8583.12106.

Matricano, D., Candelo, E., Sorrentino, M. and Cappiello, G. (2020), "Investigating the link between intellectual capital and open innovation processes: a longitudinal case study", Journal of Intellectual Capital, Vol. ahead-of-print No. ahead-of-print, doi: 10.1108/JIC-02-2020-0020.

Meles, A., Porzio, C., Sampagnaro, G. and Verdoliva, V. (2016), "The impact of the intellectual capital efficiency on commercial banks performance: evidence from the US", Journal of Multinational Financial Management, Vol. 36, pp. 64-74, doi: 10.1016/j.mulfin.2016.04.003.

Naqshbandi, M.M. and Jasimuddin, S.M. (2018), "Knowledge-oriented leadership and open innovation: role of knowledge management capability in France-based multinationals", International Business Review, Vol. 27 No. 3, pp. 701-713, doi: 10.1016/j.ibusrev.2017.12.001.

Nold, H.A. (2012), "Linking knowledge processes with firm performance: organizational culture", Journal of Intellectual Capital, Vol. 13 No. 1, pp. 16-38, doi: 10.1108/14691931211196196.

Nonaka, I. and Takeuchi, H. (2019), The Wise Company: How Companies Create Continuous Innovation, Oxford University Press, New York, NY.

Nonaka, I., Toyama, R. and Konno, N. (2000), "SECI, BA and leadership: a unified model of dynamic knowledge creation”, Long Range Planning, Vol. 33 No. 1, pp. 5-34, doi: 10.1016/S0024-6301(99) 00115-6.

North, D.C. (1990), Institutions, Institutional Change and Economic Performance, Cambridge University Press, New York, NY.

Olaisen, J. and Revang, O. (2018), "Exploring the performance of tacit knowledge: how to make ordinary people deliver extraordinary results in teams", International Journal of Information Management, Vol. 43, pp. 295-304, doi: 10.1016/j.jijnfomgt.2018.08.016.

Oliveira, M., Curado, C., Balle, A.R. and Kianto, A. (2020), "Knowledge sharing, intellectual capital and organizational results in SMES: are they related?", Journal of Intellectual Capital, Vol. 21 No. 6, pp. 893-911, doi: 10.1108/JIC-04-2019-0077.

Pérez López, S., Manuel Montes Peón, J. and José Vázquez Ordás, C. (2004), "Managing knowledge: the link between culture and organizational learning", Journal of Knowledge Management, Vol. 8 No. 6, pp. 93-104, doi: 10.1108/13673270410567657.
Leadership, culture, intellectual capital 
JIC

22,7

Peler, M., Boydell, T. and Burgoyne, J. (1989), "Towards the learning company", Management Learning, Vol. 20 No. 1, doi: 10.1177/135050768902000101.

Pellegrini, M.M., Ciampi, F., Marzi, G. and Orlando, B. (2020), "The relationship between knowledge management and leadership: mapping the field and providing future research avenues", Journal of Knowledge Management, Vol. 24 No. 6, pp. 1445-1492, doi: 10.1108/JKM-01-2020-0034.

Podsakoff, P.M. and Organ, D.W. (1986), "Self-reports in organizational research: problems and prospects", Journal of Management, Vol. 12 No. 4, pp. 531-544, doi: 10.1177/014920638601200408.

Polanyi, M. (1966), The Tacit Dimension, University of Chicago Press, Chicago, IL.

Rastogi, P.N. (2000), "Knowledge management and intellectual capital - the new virtuous reality of competitiveness", Human Systems Management, Vol. 19 No. 1, pp. 39-48, doi: 10.3233/HSM2000-19105.

Reagans, R. and McEvily, B. (2003), "Network structure and knowledge transfer: the effects of cohesion and range", Administrative Science Quarterly, Vol. 48 No. 2, pp. 240-267, doi: 10.2307/ 3556658.

Saint-Onge, H. (1996), "Tacit knowledge the key to the strategic alignment of intellectual capital", Planning Review, Vol. 24 No. 2, pp. 10-16, doi: 10.1108/eb054547.

Santos-Rodrigues, H., Faria, J., Cranfield, D. and Morais, C. (2013), "Intellectual capital and innovation: a case study of a public healthcare organisation in Europe", Electronic Journal of Knowledge Management, Vol. 11 No. 4, pp. 361-372.

Schwartz, T. (2018), "Leaders focus too much on changing policies, and not enough on changing minds", Harvard Business Review, available at: https:/hbr.org/2018/06/leaders-focus-too-muchon-changing-policies-and-not-enough-on-changing-minds (accessed 21 January 2021).

Seleim, A.A.S. and Khalil, O.E.M. (2011), "Understanding the knowledge management-intellectual capital relationship: a two-way analysis", Journal of Intellectual Capital, Vol. 12 No. 4, pp. 586-614, doi: 10.1108/14691931111181742.

Senge, P.M. (2006), The Fifth Discipline, the Art and Practice of the Learning Organization, Doubleday/ Currency, New York, NY.

Shao, Z., Feng, Y. and Liu, L. (2012), "The mediating effect of organizational culture and knowledge sharing on transformational leadership and enterprise resource planning systems success: an empirical study in China", Computers in Human Behavior, Vol. 28 No. 6, pp. 2400-2413, doi: 10. 1016/j.chb.2012.07.011.

Shao, Z., Feng, Y. and Wang, T. (2017), "Charismatic leadership and tacit knowledge sharing in the context of enterprise systems learning: the mediating effect of psychological safety climate and intrinsic motivation", Behaviour and Information Technology, Vol. 36 No. 2, pp. 194-208, doi: 10. 1080/0144929X.2016.1221461.

Spector, P.E. and Brannick, M.T. (2011), "Methodological urban legends: the misuse of statistical control variables", Organizational Research Methods, Vol. 14 No. 2, pp. 287-305, doi: 10.1177/ 1094428110369842.

Statistics Poland (2017), Yearbook of Labour Statistics, 2017, Warsaw.

Sullivan, P.H. (2000), Value-driven Intellectual Capital: How to Convert Intangible Corporate Assets into Market Value, John Wiley \& Sons, New York, NY.

Tsui, E., Wang, W.M., Cai, L., Cheung, C.F. and Lee, W.B. (2014), "Knowledge-based extraction of intellectual capital-related information from unstructured data", Expert Systems with Applications, Vol. 41 No. 4, pp. 1315-1325, doi: 10.1016/j.eswa.2013.08.029.

Vagnoni, E. and Oppi, C. (2015), "Investigating factors of intellectual capital to enhance achievement of strategic goals in a university hospital setting", Journal of Intellectual Capital, Vol. 16 No. 2, pp. 331-363, doi: 10.1108/jic-06-2014-0073.

Wang, Z., Wang, N. and Liang, H. (2014), "Knowledge sharing, intellectual capital and firm performance”, Management Decision, Vol. 52 No. 2, pp. 230-258, doi: 10.1108/MD-02-2013-0064. 
Watkins, K.E. and Kim, K. (2018), "Current status and promising directions for research on the learning organization”, Human Resource Development Quarterly, Vol. 29 No. 1, pp. 15-29, doi: 10. 1002/hrdq.21293.

Watkins, K.E. and Marsick, V.J. (1996) (Eds), Action: Creating the Learning Organization, American Society for Training and Development, Alexandria, VA.
Leadership, culture, intellectual capital

Yang, J., Brashear, T.G. and Asare, A. (2015), "The value relevance of brand equity, intellectual capital and intellectual capital management capability", Journal of Strategic Marketing, Vol. 23 No. 6, pp. 543-559, doi: 10.1080/0965254X.2014.1001863.

Zappa, P. and Robins, G. (2016), "Organizational learning across multi-level networks", Social Networks, Vol. 44, pp. 295-306, doi: 10.1016/j.socnet.2015.03.003.

\section{Appendix}

The appendix is available online for this article: https://www.researchgate.net/publication/354859494 Leadership_Culture_Intellectual_Capital_and_Knowledge_Processes_for_Organizational_ Innovativeness_across_Industries_The_Case_of_Poland_Appendices

\section{Corresponding author}

Wioleta Kucharska can be contacted at: wioleta.kucharska@pg.edu.pl

For instructions on how to order reprints of this article, please visit our website: 